Carbon dioxide capture from combustion flue gases with a calcium oxide chemical loop. Experimental results and process development.

Mónica Alonso

Instituto Nacional del Carbón, CSIC-INCAR, Francisco Pintado Fe, 26, 33011 Oviedo, Spain

T.: 34-985119090 F.: 34-985297662

e-mail:mac@incar.csic.es 


\title{
Carbon dioxide capture from combustion flue gases with a calcium oxide chemical loop. Experimental results and process development
}

\author{
M Alonso ${ }^{\mathrm{a}}$, N Rodríguez ${ }^{\mathrm{a}}, \mathrm{B}$ González ${ }^{\mathrm{a}}, \mathrm{G} \mathrm{Grasa}^{\mathrm{b}}, \mathrm{R}^{\mathrm{R}}$ Murillo $^{\mathrm{b}}, \mathrm{J}$ C \\ Abanades ${ }^{a}$ \\ ${ }^{a}$ Instituto Nacional del Carbon, CSIC-INCAR Spanish Research Council (Oviedo-Spain) \\ ${ }^{b}$ Instituto de Carboquímica, CSIC-ICB Spanish Research Council (Zaragoza-Spain)
}

\begin{abstract}
Post-combustion carbonate looping processes are based on the capture of carbon dioxide from the flue gases of an existing power plant in a circulating fluidized bed reactor (CFB) of calcium oxide (the carbonator) particles. The calcination of calcium carbonate in a new oxyfired CFBC power plant regenerates the sorbent (calcium oxide particles) and obtains high purity carbon dioxide. This communication presents experimental results from a small test facility $(30 \mathrm{kWt})$ operated in continuous mode using two interconnected CFB reactors as carbonator and calciner. Capture efficiencies between 70 and $97 \%$ have been obtained under realistic flue gas conditions in the carbonator reactor (temperatures around $650^{\circ} \mathrm{C}$ ). The similarity between process conditions and those existing in CFBC power plants should allow a rapid scaling up of this technology. The next steps for this process development are also outlined.
\end{abstract}

Keywords: $\mathrm{CO}_{2}$ capture, carbonate looping, carbonation, calcination, pilot testing 


\section{Introduction}

Reducing the capture cost and the energy efficiency penalties are the primary driving forces that justify the development of new carbon dioxide capture systems. It is widely recognized that there is scope for large reductions in capture costs by applying new concepts for separating carbon dioxide in the capture system (Metz et al., 2005 ). Among the new concepts for carbon dioxide capture, it is important to distinguish between two categories. The first refers to totally new processes, with no analogous reactors of a sufficiently large scale in operation today. These technologies require a full scaling up from basic principles tested only in the laboratory or in the computer. The second category refers to new concepts that rely on the use of new functional materials in reactors already commercially established on a large scale (e.g., a new solvent for absorption columns or a new solid sorbent in a circulating fluidized bed system). The process discussed in this work falls into the second category.

The carbon dioxide capture process discussed in this paper was originally proposed ten years ago (Shimizu et al., 1999), and uses calcium oxide as a regenerable sorbent to capture carbon dioxide from combustion flue gases. Other regenerable processes using calcium oxide in gasification systems have been proposed as early as the XIX century (Squires, 1967). Modern versions are still under development, and others have been proposed for natural gas reforming applications (Harrison, 2008), but will not be discussed any further here. The current understanding of the sorbent fundamentals has also been reviewed recently (Anthony, 2008; Harrison, 2008). It is well known that calcium oxide particles can react sufficiently fast with carbon dioxide only up to a certain level of conversion, marked by the formation of a product layer (Alvarez and Abanades, 2005) of calcium carbonate on all free 
surfaces of calcium oxide (including interior surfaces). The sintering (loss interior surface) of calcium oxide translates into rapid decay in the carbon dioxide capture capacity as the number of calcination-carbonation cycles increases (Barker, 1973; Curran, 1967), and this has been the subject of much concern about the viability of the reversible carbon dioxide capture process based on calcium oxide (Anthony, 2008). A substantial R\&D effort is still devoted to better understand and reduce this decay and/or to formulate alternative methods for sorbent pretreatment and reactivation (Anthony, 2008). However, it has also been recently established (Grasa and Abanades, 2006) that a residual activity exits (7-8\% points of calcium conversion to calcium carbonate) that remains stable after many hundred of carbonation calcination cycles, and that could be able to sustain the operation of the capture process if sufficiently large solid circulation rates are allowed between the carbonator and calcination units. This is another reason why circulating fluidized bed technology should be from now the main subject of application of these calcium oxide looping concepts in postcombustion applications.

A schematic of overall carbon dioxide capture system as proposed by Shimizu et al. (Shimizu et al., 1999) is presented in Fig. 1. Carbon dioxide is captured from the combustion flue gas of an existing power plant in a circulating fluidized bed carbonator operating between $600-700^{\circ} \mathrm{C}$. The solids leaving the carbonator (with a certain conversion of calcium oxide to calcium carbonate) are directed to a second fluidized bed where calcination/regeneration takes place. Coal burns in the calciner in an atmosphere of oxygen/carbon dioxide at temperatures over $900^{\circ} \mathrm{C}$ to produce the heat necessary to calcine the calcium carbonate back to calcium oxide and carbon dioxide. This second fluidized bed calciner operates with oxygen supplied by an air separation unit. The carbon dioxide captured from the flue gases as calcium carbonate and the carbon dioxide resulting from the 
oxy-fired combustion of coal in the calciner, are recovered in concentrated form in the calciner gas and are suitable for final purification and compression. The calciner requires a relevant fraction $(40-50 \%)$ of the total energy entering the system in order to heat the incoming gas and solids streams up to calciner temperatures and to provide the heat that drives the endothermic calcination of calcium carbonate (Rodriguez et al., 2008a). However, this energy leaves the system in mass streams at high temperature (at $\mathrm{T}>900^{\circ} \mathrm{C}$ ) or is recovered as carbonation heat in the carbonator (at around $650^{\circ} \mathrm{C}$ ) in order to drive a highefficiency steam cycle (Abanades et al., 2004b; Harrison, 2008; Romeo et al., 2008). This is a distinctive characteristic of this capture system with respect to any other carbon dioxide capture system: it is possible to generate additional power from the various high-temperature sources in the capture system. The calciner is in fact a new oxy-fired fluidized bed power plant (dotted boundary in Figure 1) that repowers the existing plant as well as capturing a large fraction of its carbon dioxide thanks to the carbonate loop. It has been shown (Anthony, 2008; Romeo et al., 2008) that the potential for high efficiencies exists in these combustion systems. Furthermore, a simple and transparent economic analysis using published cost data available on the main blocks of the system of Figure 1 (the existing combustion power plant, the new oxyfired power plant acting as calciner and the circulating fluidized bed reactor between them acting as carbonator) shows that there is clear scope for a breakthrough in capture cost to around $70 \%$ of the carbon dioxide avoided cost of the equivalent stand alone oxyfired system (Abanades et al., 2007). As mentioned earlier, a serious drawback of the process is that for all these benefits to be realized, it is critical that sorbent cost (fresh limestone make up to maintain the activity of the sorbent in the carbonate loop) be negligible (Abanades et al., 2004b). The cost of the sorbent make up could be very high in some locations if the capture system generates a large purge of solids cannot be used. The purge will be made up of a mixture of ash from the fuel used in the calciner, deactivated calcium 
oxide with a minor fraction of calcium sulphate if sulfur was present in the fuel used in the calciner and/or in the flue gas entering the carbonator. However, this cost should be affordable in many locations where cheap limestone is available (Rodriguez et al., 2008b) and/or there is a strong demand for calcium oxide for cement production. Also, it has recently been found (Grasa et al., 2008) that the deactivated material resulting from the carbonation-calcination loop is a very effective sorbent of sulphur dioxide under CFBC conditions. Therefore, the purge of calcium oxide solids from the carbonation loop (that in terms of mass flows is comparable to the limestone requirements for desulphurization in CFBC boilers burning high sulfur fuels) could be fed to the boiler generating the flue gases (or to the flue gas desulfurization system associated with such a boiler) minimizing in this way the net consumption of limestone respect to the reference system without capture.

The ability of a fluidized bed reactor of calcium oxide operating at $650^{\circ} \mathrm{C}$ to effectively capture carbon dioxide at typical concentrations of combustion flue gases at atmospheric pressure, has already been demonstrated in practice (Abanades et al., 2004a) in experiments in a batch fluidized bed of calcium oxide with reasonable gas residence times and bed inventories. These results have recently been validated in continuous mode, in a bubbling fluidized bed carbonator (Lu et al., 2008) coupled with an oxyfired circulating fluidized bed calciner. Variations of this carbonation-calcination system are planned to be tested at small pilot scale (10s of kW) in ongoing projects in France, UK, Germany, Canada and Spain under the EU C3-capture project and other national projects. This paper presents the first experimental evidence of the full concept operating a circulating fluidized bed carbonator reactor absorbing carbon dioxide from flue gases in continuous mode. 


\section{Experimental}

Experiments have been conducted in a $30 \mathrm{~kW}$ test facility fully designed and built at CSIC, made up of two interconnected circulating fluidized bed reactors as shown in Figure 2. Both reactors have a $0.1 \mathrm{~m}$ internal diameter; the calciner is $6 \mathrm{~m}$ in height and the carbonator $6.5 \mathrm{~m}$ in height. Some experiments presented here were carried out in a previous rig set-up, similar to the current one, but with riser heights of $3.2 \mathrm{~m}$. In both set ups, each riser is connected to a high efficiency primary cyclone. The solids fall from the cyclone through a vertical standpipe to a bubbling fluidized bed loop seal. Solids flow over the loop seals towards an inclined standpipe that directs them to the opposite reactor (i.e solids captured in the primary cyclone of the carbonator are directed towards the calciner) at which point they have completed half of the solid circulation loop. There is a bypass just below the loop seals to extract solid samples and to measure solid circulation rates ( $\mathrm{Gs}, \mathrm{in} \mathrm{kg} / \mathrm{m}^{2} \mathrm{~s}$ ) by diverting solids to a dead volume for a certain period of time. Other solid samples can also be extracted directly from several riser ports for more detailed analysis. Two secondary cyclones and gas bypass with filters complete the gas flow paths of the carbonator and of the calciner.

A mixture of gas containing carbon dioxide (air from a blower and carbon dioxide from a Dewar) is fed into the carbonator simulating the flue gas. No air distributor is used for these small diameter risers, allowing the easy feed of solids when needed (screw feeders for solid fuels, in particular for the air-fired calciner, are not shown in the Figure 2 for simplicity). The loop seals are aerated with air. Electric ovens surround the first $2.5 \mathrm{~m}$ of the risers (six independently controlled heating elements in each) and also the loop seals. After start up, the 
ovens are switched off in the carbonator and even opened up slightly in order to release the excess heat generated in the carbonation reaction.

In the second circulating fluidized bed reactor, the calcium carbonate formed in the carbonator is regenerated under typical combustion conditions in a CFBC $\left(800-900^{\circ} \mathrm{C}\right.$ with 2-6\% air excess). The calciner is air-fired in these particular experiments. As mentioned in the introduction, oxy-fired combustion would be necessary in large scale systems, operating at temperatures well over $900^{\circ} \mathrm{C}$ to provide the necessary driving force for the fast calcination of $\mathrm{CaCO}_{3}$ in $\mathrm{CO}_{2}$ rich atmospheres. It could therefore be argued that our calcination conditions were too mild and not sufficiently representative of the large scale systems. However, there is strong evidence that typical calcination temperatures and atmospheres in the calciner do not affect much the overall sorbent performance as long as temperatures are kept below $1000^{\circ} \mathrm{C}$ (González et al., 2008). This is also supported by early works conducted by (Curran, 1967) under very high temperatures (up to $1060^{\circ} \mathrm{C}$ ) (in fluidized bed combustion) and yielding similar deactivation curves of the sorbent than at more moderate conditions. Furthermore, it has been recently shown by independent experiments in fluidized beds (Lu et al., 2008) that fast calcination in rich $\mathrm{CO}_{2}$ atmospheres is feasible in CFB oxy-fired conditions.

Continuous analyses of gases (carbon dioxide, oxygen and carbon monoxide and others) can be carried out from different points in the installation. Zirconia oxygen probes are also present in the risers to measure local oxygen content, ensuring good quality of combustion in the calciner and adding confidence to the gas composition measurements by the analyzer. This is particularly important in this small test rig because aeration in the loop seal can amount to $20 \%$ of the total flow of gas entering the risers and there is uncertainty about the 
path of this aeration gas. In normal circulation conditions, it should follow the circulating solids downwards towards the riser, and the oxygen probe should give the same average oxygen content as the gas analyzer. However, under some conditions of low solid circulation rates, a fraction of the air fed into the loop seal travels upwards towards the cyclone (lowering its solids capture efficiency). In these conditions, that where more common in the early test set-up with risers $3.2 \mathrm{~m}$ high, the oxygen content measured by the zirconia probe at the exit of the riser is smaller that measured by the gas analyzer (which samples gas after the secondary cyclone).

Finally, as can be seen in Figure 2 there are a number of ports for installing differential pressure transducers and thermocouples. All these signals, together with those from the oxygen probes, the mass flow controllers and the gas analysis system are collected in a computer.

All the solid samples taken from the calciner, the carbonator and the loop seals are analysed to determine total calcium oxide content and calcium conversion to calcium carbonate. Selected samples from the carbonator are taken to measure the carbonation reaction rate in a thermobalance specially designed for multi-cycle experiments (see (González et al., 2008)). A typical high purity limestone (>98\% calcium carbonate) was used in all the experiments, with a particle size range below 350 microns and with activity curves that have been reported elsewhere (González et al., 2008).

In a characteristic run, a batch of $20 \mathrm{~kg}$ of limestone is loaded into the loop seals and the risers. Temperatures are allowed to rise up to around $600^{\circ} \mathrm{C}$ with electric heating and from that point fuel is fed into both risers in order to increase the temperature to calcination 
conditions. Due to the high heat losses from this small rig, several hours are necessary to complete calcination of the initial batch of solids. Furthermore, attrition during the first calcination of limestone is intense (in particular in the rig of Figure 2, which has high velocity sections because of the high efficiency cyclones). Therefore, batches of fresh limestone had to be added occasionally to maintain the solids inventories and solids circulation rates, thereby increasing even further the total calcination time of the first batch of material. Future tests incorporating some suggested solutions to mitigate attrition losses (e.g. partial sulfation and/or controlled precalcination as proposed in (Jia et al., 2007)) will be carried out in the future. But it is important to highlight that attrition losses are mainly relevant in the first calcination cycles and therefore, all the know-how and mechanical tests designed to make a suitable choice limestones for commercial CFBC boilers should be of application for carbonate looping cycles. Once the material had been calcined, solids in the circulation loop had a typical average particle size distribution below 100 microns with this particular limestone, and attrition was no longer a serious problem. Solids collected in the secondary cyclones were fed back to the main circulation loop. The bed inventory in each riser was calculated assuming that the pressure drop measured in the riser is due to the bed inventory $(\mathrm{W})$ as in minimum fluidization conditions $(\Delta \mathrm{P}=\mathrm{W} / \mathrm{A})$.

\section{Results and Discussion}

Before discussing some of the results obtained during the carbonation-calcination test, it may be useful to report on the main problems and difficulties found before these tests were successfully completed. There were some fundamental problems associated with the initial rig design that had to be limited to a height of $3.2 \mathrm{~m}$ for space limitations in the building. In addition, the original cyclones were not operating with sufficient efficiency (92-97\%), and as 
a result, the total solids inventory in the main circulation loop could only be maintained for relatively short periods of time. This was compensated for by re-injecting frequently to the circulation loop the solids collected from the secondary cyclone. In these conditions, a dynamic type of operation was attained. An example of the type of information obtained from a typical test in the $3.2 \mathrm{~m}$ installation is shown in Figure 3. The plot at the top includes the temperatures along the riser height of the carbonator. The plot in the centre shows the carbon dioxide concentration (black line) measured at the exit of the secondary cyclone, with occasional measurements also taken from the gas inlet entering the carbonator. The light and dark grey lines are oxygen measurements from the zyrconia oxygen probe and from the analyzer. The plot at the bottom of the Figure shows the continuous recording of the pressure drop in the carbonator risers with some points indicating the solids circulation measurements. This particular experiment was carried out with partially deactivated sorbent material from previous experiments. As can be seen, the carbonator retained good axial isothermicity $( \pm$ $20^{\circ} \mathrm{C}$ ) at any particular time when circulation rates were above $1 \mathrm{~kg} / \mathrm{m}^{2} \mathrm{~s}$. Superficial gas velocities were varied between 1.5 and $3 \mathrm{~m} / \mathrm{s}$. As discussed above, this particular rig (risers of only $3.2 \mathrm{~m}$ height and low efficiency primary cyclones) only retains relatively low stable solids circulation rates and bed inventories $\left(0.5 \mathrm{~kg} / \mathrm{m}^{2} \mathrm{~s}\right.$ and pressure drops between $5-10 \mathrm{~cm}$ $\mathrm{H}_{2} \mathrm{O}$ ). The addition of batches of solids to the carbonator (see for example at 13:35) translates into a rapid increase of the solids inventory in the riser, a rapid drop in the carbon dioxide concentration of the gas coming from the carbonator and a sharp increase in the solids circulation rates (see also the perfect isothermity of the riser under these conditions). These situations occur when capture efficiencies are well over 95\%, close to the maximum allowed by the equilibrium of carbon dioxide on calcium oxide at the average temperature of the carbonator reactor. Unfortunately, as discussed above, it was not possible to maintain this situation for more than a few minutes in the $3.2 \mathrm{~m}$ height rig, and as the solids abandoned the 
primary circulation loop, carbon dioxide capture efficiency decreased rapidly. Many experiments like this one were carried out using different starting materials (different activities), different gas velocities in the carbonator (between 1.5 and $3.5 \mathrm{~m} / \mathrm{s}$ ) and with different carbon dioxide contents in the gas that entered the carbonator. These conditions provided a good base for the development and validation of a model and for the practical design of the modified rig in Figure 2.

Although these were non-stationary conditions respect to the solid circulation and inventories, it is important to highlight that the gas residence time in the $3.2 \mathrm{~m}$ carbonator was only 1-2 seconds in all experiments. Therefore, the experimental carbon dioxide capture efficiencies measured in the gas phase from the carbon dioxide flow fed into the carbonator and the carbon dioxide measured at in the flue gas at the exit of the carbonator, are established "instantly" for a given value of bed inventory and average activity of the solids in the bed. This was already discussed in (Abanades et al., 2004a), where it was possible to fit with a stationary state bubbling model for the gas phase the experimental efficiencies measured with a batch of solids of changing composition with time. The key variable introduced to allow the interpretation of results with this approach was the fraction of active calcium oxide reacting in the fast reaction regime $\left(f_{a}\right)$ at any time, that was defined as the difference between the maximum carbonation conversion achievable by the solids in the bed $\left(\mathrm{X}_{\max }\right)$ and the actual carbonation conversion of the solids in the bed $\left(\mathrm{X}_{\mathrm{carb}}\right)$. Therefore, it is also possible to assume here that for any time during the experiment, the perfectly mixed bed of solids in the carbonator contains (in the absence of sulphur and ash) three types of solids: a fraction of inactive calcium oxide from previous carbonation-calcination cycles $\left(1-\mathrm{X}_{\max }\right)$, a fraction of calcium carbonate given by the carbonation conversion $\left(\mathrm{X}_{\text {carb }}\right)$, and a fraction of active calcium oxide, $f_{a}$, that is the only responsible of the effective absorption of carbon 
dioxide from the gas phase. Using this concept, combined with submodels for reaction rates of this active fraction of calcium oxide and assumptions of ideal reactor for the CFB carbonator and calciner, full reactor models have recently been formulated (Alonso et al., 2009; Hawthorne et al., 2008) for the carbonator. These models provide a great source of information for gaining confidence in the process. However, from a practical point of view, it is very important to demonstrate the possibility of operating the system in continuous mode respect to the solid circulation between carbonator and calciner. It was clear from the test in the experimental set up with risers heights of only $3.2 \mathrm{~m}$, that gas velocities in the CFB carbonator higher than $2 \mathrm{~m} / \mathrm{s}$ and lime particle sizes around 100 microns, only allowed for very modest solid inventories in the carbonator. Stable efficiencies associated with these modest inventories where typically below 30\%. Efficiencies higher than $95 \%$ where only possible for short periods of time (5-10 minutes) soon after injection of batches of material to the circulation loop (see example of Figure 3).

Figure 4 presents some results for the same rig after the extension of the riser heights (carbonator height up to $6.5 \mathrm{~m}$ and calciner height up to $6 \mathrm{~m}$ ) and reconstruction of high efficiency cyclones. The results are qualitatively identical to the previous ones, but much more stable in terms of solids circulation rates and the bed inventory in the carbonator. For the sake of simplicity, the experimental information on gas compositions has been plotted as instant capture efficiency (black dotted lines) calculated from the experimental concentration of carbon dioxide at the exit of the carbonator. These capture efficiencies are compared with the maximum efficiency allowed by the equilibrium at the average temperature in the carbonator reactor at that particular time. As can be seen in the Figure on the left hand side, carbon dioxide capture efficiencies are consistent and stable to over $70 \%$ and close to $90 \%$ (superficial gas velocities between $2.0-2.1 \mathrm{~m} / \mathrm{s}$, solids circulation rates of $0.8-2.3 \mathrm{~kg} / \mathrm{m}^{2} \mathrm{~s}$, 
average temperature $650^{\circ} \mathrm{C}$ ). However, there are two events in this figure that show a much lower capture efficiency, illustrating once again the importance of a good solids circulation and sufficient solids inventory in the riser. The first event (at around 22:15) corresponds to the deliberate switching off of the aeration of the loop seal, which interrupted the solids circulation to the carbonator. As a result, efficiency dropped to zero as due to the lack of solids reacting in the carbonator. In addition, in the absence of the exothermic carbonation reaction and a continuous supply of solids from the loop seal, the temperature dropped in the carbonator reactor, as indicated by the sharp increase in theoretical capture efficiency allowed by the equilibrium. The second low efficiency peak in the same figure at around 22:40 corresponds to a measurement of the solids circulation rate (when solids were diverted to a container for a certain period of time) that translates into a rapid reduction of the solids inventory in the carbonator and an associated reduction in capture efficiency.

Figure 5 corresponds to an experimental period conducted under similar conditions but with calcium oxide particles highly deactivated and close to the residual activity of the limestones (0.07-0.12) after hundreds of carbonation calcination cycles (Grasa and Abanades, 2006). This particular experiment ran for more than eight hours under stable conditions, with carbon dioxide capture efficiencies between $65-75 \%$, with relatively modest circulation rates $\left(1-1.8 \mathrm{~kg} / \mathrm{m}^{2} \mathrm{~s}\right)$ and solids inventories. Higher efficiencies would be feasible in taller risers and/or with fluid dynamic improvement in order to sustain higher circulation rates and higher solids inventories in the carbonator. The low efficiencies measured on the left hand side of the Figure correspond to a period when the ovens of the calciner were switched off. This caused the temperatures in the calciner to drop below $750^{\circ} \mathrm{C}$ and calcination intensity to fall. In addition, progressive carbonation of the material in the system led to low (eventually zero) capture efficiencies. When the ovens were switched on at 17:15, 
calcination intensity was restored and capture efficiencies recovered in less than one hour to a stable value of between $70-75 \%$. Since the activity of the sorbent was close to its residual value and did not change with time, it was possible to restore these conditions and efficiency values after six hours of continuous operation under other conditions.

\section{Future work}

The results presented above, together with the increasing number of new information published by other authors (see (Hawthorne et al., 2008), and previous papers reviewed in (Anthony, 2008; Harrison, 2008)) from laboratory and bench scale results, supports the technical and economic viability of carbonate looping cycles, as represented in Figure 2. The focus of ongoing work at CSIC is on the development of the carbonator reactor, assuming that technology for oxy-fired circulating fluidized bed combustion will be available to serve as calciner (Figure 2). As the results have shown, it is feasible to design a CFB carbonator as a very effective carbon dioxide absorber as long as this reactor is supplied with a continuous flow of calcium oxide to match the carbon dioxide flow to be captured. High calcium conversions of the solids to calcium carbonate are note required, because gas densities are three orders of magnitude lower than solid densities and even with carbonation conversions as low as $5 \%$ it is possible to capture the carbon dioxide using Solid/Gas mass ratios below 20, typically used in existing large scale CFB boilers. Only heat balance considerations (Rodriguez et al., 2008a) prevent lower carbonation conversions to be used. However, research on how to improve sorbent performance can only lead to higher benefits and cost savings for this technology (Anthony, 2008).

As regards to the oxy-fired calciner, one can anticipate that the introduction of an endothermic reaction (continuous calcination) to the oxyfired combustor will only bring 
benefits in terms of heat management and temperature control in the highly exothermic combustion reaction that takes place in an oxyfired CFB combustor. The link of carbonate looping processes with oxyfired CFB technology is one the strengths of the process of Figure 2 but it is also the source of the weakest point with respect to more exotic emerging carbon dioxide capture systems: the need for an air separation unit to drive the calciner of Figure 2, still entails a substantial energy and cost penalty. However, we are pursuing advanced carbonate lopping processes where there is no need for an oxygen fired calciner because part of the heat generated in the main combustion chamber of the power plant is transferred (by circulating calcium oxide particles and refractory ash) to a calciner operating at as low temperature as possible thanks to the dilution of carbon dioxide with steam. Aspen Hysys simulations have proven that the combustor and the calciner in this configuration can be designed as adiabatic reactors, and it is possible to recover the energy produced in the carbonator to produce overheated steam. These theoretical calculations (Murillo et al., 2009) have shown that when a sub-critical Rankine cycle is used and a moderate thermal integration is performed, there is very low energy penalty other than the penalty associated to carbon dioxide purification and compression. Tests conducted at small laboratory scale (González et al., 2008) have shown that the calcium oxide particles may maintain sufficient activity under the typical high temperature conditions (around $1000^{\circ} \mathrm{C}$ ) and atmosphere of such a system.

The test facility used in this work (Figure 2) will continue to be used to obtain more data on the behavior of different limestones in the system, the effect of sulphur and ash contents on the fuels used, etc. Plans for a $1 \mathrm{MW}$ scaling up in a real industrial environment (the 50MWe CFB power plant of Hunosa in La Pereda, Asturias, Spain) have already been initiated, with an aggressive schedule in order that the first experimental campaigns starts in 
the 1 MW rig by the end of 2010. The successful tests conducted so far make us feel optimistic about the next steps and about the speed at which results can be escalated, because the key components for carbonate looping post-combustion systems are mechanically similar to already existing large scale circulating fluidized bed combustors and their emerging oxyfired counterparts.

\section{Conclusion}

Carbonate looping cycles are very promising concepts for post-combustion carbon dioxide capture applications. This work has shown that the new key piece of equipment, the CFB carbonator, works as an effective carbon dioxide absorber when supplied with a sufficient flow of active calcium oxide. Temperatures, solid circulation rates and bed inventories associated to the operation of the carbonator are relatively mild, compared to the established operating conditions for large scale CFBC boilers. Furthermore, since the carbonation is a fast exothermic reaction that takes place between $600-700{ }^{\circ} \mathrm{C}$, the large amount of energy supplied to the calciner to regenerate calcium carbonate back to calcium oxide and carbon dioxide can be recovered from the carbonation heat output. The carbonator can be designed as an interface between an existing power plant and a new oxy-fired CFB power plant that is acting as calciner. The oxy-fired CFBC is not only avoiding the carbon dioxide from its own coal combustion feed, but also all the carbon dioxide coming from the flue gases of the neighbouring power plant, that have been captured as calcium carbonate in the carbonator. Future designs of carbonate looping cycles may even lead to further savings in energy and costs by integrating the combustion chamber with the calciner.

Experimental results from a $30 \mathrm{~kW}$ test facility designed, constructed and operated by CSIC (Spain) have demonstrated the essential viability of the process. The results were using 
a rig configuration that included different riser heights and cyclone designs and allowed obtained longer periods of stable solids circulation rates and bed inventories. Attrition of the limestone was very intense in the first calcinations but the remaining solids showed little tendency to further attrition. The carbonator reactor functions as an effective absorber of carbon dioxide (efficiency higher than $70 \%$ ) as long as there is a sufficient bed inventory and solids circulation rate, even with highly deactivated calcium oxide (activity lower than 0.3 and even close to the residual activity below the typical 0.1 of sorbents cycled hundreds of times). Plans have already been made to extend the experimental database and gain experience and design data for the next 1MW scale pilot.

\section{Acknowledgement}

This work has been carried out thanks to the financial support from the Spanish companies Hunosa and Endesa. Experimental help provided by F Fuentes and I Rodríguez is also acknowledged.

\section{References}

Abanades, J. C., Anthony, E. J., Lu, D. Y., Salvador, C., Alvarez, D., 2004a. Capture of $\mathrm{CO}_{2}$ from combustion gases in a fluidized bed of $\mathrm{CaO}$. Aiche Journal 50, 1614-1622.

Abanades, J. C., Grasa, G., Alonso, M., Rodriguez, N., Anthony, E. J., Romeo, L. M., 2007. Cost structure of a postcombustion $\mathrm{CO}_{2}$ capture system using $\mathrm{CaO}$. Environmental Science \& Technology 41, 5523-5527.

Abanades, J. C., Rubin, E. S., Anthony, E. J., 2004b. Sorbent cost and performance in $\mathrm{CO}_{2}$ capture systems. Industrial \& Engineering Chemistry Research 43, 3462-3466.

Alonso, M., Rodríguez, N., Grasa, G., Abanades, J. C., 2009. Modelling of a fluidized bed carbonator reactor to capture $\mathrm{CO} 2$ from a combustion flue gas. Chemical Engineering Science 64, 883-891.

Alvarez, D., Abanades, J. C., 2005. Determination of the critical product layer thickness in the reaction of $\mathrm{CaO}$ with $\mathrm{CO}_{2}$. Industrial \& Engineering Chemistry Research 44, $5608-5615$. 
Anthony, E. J., 2008. Solid Looping Cycles: A New Technology for Coal Conversion. Industrial \& Engineering Chemistry Research 47, 1747-1754.

Barker, R., 1973. Reversibility of the reaction $\mathrm{CaCO}_{3}=\mathrm{CaO}+\mathrm{CO}_{2}$. J Appl Chem Biotechnol 23, 733-742.

Curran, G. P., Fink, C. E., Gorin, E., 1967. $\mathrm{CO}_{2}$ acceptor gasification process. Studies of acceptor properties. Adv. Chem. Ser. 69, 141-161.

González, B., Grasa, G. S., Alonso, M., Abanades, J. C., 2008. Modeling of the deactivation of $\mathrm{CaO}$ in a carbonate loop at high temperatures of calcination. Industrial and Engineering Chemistry Research 47, 9256-9262.

Grasa, G. S., Abanades, J. C., 2006. $\mathrm{CO}_{2}$ capture capacity of $\mathrm{CaO}$ in long series of carbonation/calcination cycles. Industrial \& Engineering Chemistry Research 45, 8846-8851.

Grasa, G. S., Alonso, M., Abanades, J. C., 2008. Sulfation of $\mathrm{CaO}$ Particles in a Carbonation/Calcination Loop to Capture $\mathrm{CO}_{2}$. Industrial \& Engineering Chemistry Research 47, 1630-1635.

Harrison, D. P., 2008. Sorption-Enhanced Hydrogen Production: A Review. Industrial \& Engineering Chemistry Research 47, 6486-6501.

Hawthorne, C., Charitos, A., Perez-Pulido, C. A., Bing, Z., Scheffknecht, G., 2008. Design of a dual fluidised bed system for the post-combustion removal of $\mathrm{CO}_{2}$ using $\mathrm{CaO}$. Part I: CFB carbonator reactor model. In: 9th International Conference on Circulating Fluidized Beds, Hamburg, Germany

Jia, L., Hughes, R., Lu, D., Anthony, E. J., Lau, I., 2007. Attrition of calcining limestones in circulating fluidized-bed systems. Industrial \& Engineering Chemistry Research 46, 5199-5209.

Lu, D. Y., Hughes, R. W., Anthony, E. J., 2008. Ca-based sorbent looping combustion for CO2 capture in pilot-scale dual fluidized beds. Fuel Processing Technology 89, 1386-1395.

Metz, B., Davidson, O., Coninck, H., de Loos, M., Meyer, L. E., 2005 Special Report on Carbon Dioxide Capture and Storage. Intergovernmental Panel on Climate Change (IPCC).

Murillo, R., Grasa, G., Martínez, I., Rodríguez, N., Abanades, J. C., 2009. Conceptual design of a three bed fluidized bed combustion system capturing $\mathrm{CO}_{2}$ with $\mathrm{CaO}$. In: 5th Trondheim Conference on $\mathrm{CO} 2$ Capture, Transport and Storage, Trondheim

Rodriguez, N., Alonso, M., Grasa, G., Abanades, J. C., 2008a. Heat requirements in a calciner of $\mathrm{CaCO}_{3}$ integrated in a $\mathrm{CO}_{2}$ capture system using $\mathrm{CaO}$. Chemical Engineering Journal 138, 148-154.

Rodriguez, N., Alonso, M., Grasa, G., Abanades, J. C., 2008b. Process for Capturing CO2 Arising from the Calcination of the $\mathrm{CaCO} 3$ Used in Cement Manufacture. Environmental Science \& Technology 42, 6980-6984.

Romeo, L. M., Abanades, J. C., Escosa, J. M., Paño, J., Giménez, A., Sánchez-Biezma, A., Ballesteros, J. C., 2008. Oxyfuel carbonation/calcination cycle for low cost CO2 capture in existing power plants. Energy Conversion and Management 49, 28092814.

Shimizu, T., Hirama, T., Hosoda, H., Kitano, K., Inagaki, M., Tejima, K., 1999. A Twin Fluid-Bed Reactor for Removal of $\mathrm{CO}_{2}$ from Combustion Processes. Chemical Engineering Research and Design 77, 62-68. 
Squires, A. M., 1967. Cyclic Use of Calcined Dolomite to Desulfurize Fuels Undergoing Gasification. Advances in Chemistry Series, 205-\&. 


\section{Figure Captions}

Figure 1. Schematic of a carbonate looping system to capture $\mathrm{CO}_{2}$ from an existing power plant, that generates more power when the oxyfired circulating fluidized bed combustor acts as calciner (area inside dotted line).

Figure 2. Schematic and overview of the interconnected circulating fluidized beds to test carbonate looping at INCAR-CSIC.

Figure 3. Example of experimental results from the carbonate looping test rig.

Figure 4. Example of experimental results for the rig of Figure 2 which operates with continuous carbonations and calcinations.

Figure 5. Example of experimental results using calcium oxide particles highly deactivated. 